\title{
CERMINAN NILAI-NILAI ISLAM DALAM KOLEKSI 366 CERITA RAKYAT MALAYSIA: SATU PENDEKATAN TAKMILAH
}

\author{
MUHAMMAD NUR AL-HAKIM MOHAMAD HANAFIAH* DAN MOHD FIRDAUS CHE \\ YAACOB
}

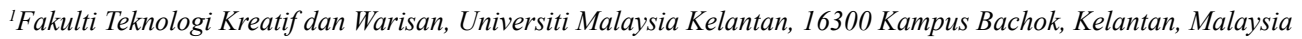

*Corresponding author: alhakim201@yahoo.com

Submitted final draft: 1 November $2020 \quad$ Accepted: 8 December $2020 \quad$ http://doi.org/10.46754/jbsd.2021.03.005

\begin{abstract}
Abstrak: Cerita rakyat sememangnya tidak asing dalam kalangan masyarakat Melayu zaman dahulu. Malang sekali ia semakin dilupakan oleh generasi zaman kini. Cerita rakyat mengandungi nilainilai Islam yang boleh dijadikan tauladan kepada rakyat. Kreativiti orang Melayu dalam mengolah cerita rakyat bukan sahaja untuk menghiburkan, malah dapat mendidik masyarakat dengan nilainilai Islam. Kajian ini berdasarkan daripada kelompongan kajian-kajian lepas yang didapati masih kurang menjalankan penelitian khususnya terhadap aspek nilai-nilai Islam. Kajian ini berusaha untuk membuka mata masyarakat mengenai nilai-nilai Islam dalam cerita rakyat. Objektif kajian ini untuk mengenal pasti dan menganalisis nilai-nilai Islam yang terdapat dalam teks Koleksi 366 Cerita Rakyat Malaysia yang berupaya mendidik masyarakat ke arah yang lebih baik. Kajian ini meninjau beberapa buah cerita rakyat yang terkandung dalam teks Koleksi 366 Cerita Rakyat Malaysia. Seterusnya, kajian ini menggunakan kaedah kualitatif sebagai metod kajian dan teori Takmilah dijadikan sebagai deduktif kajian yang akan mengukuhkan pada bahagian analisis. Tiga prinsip utama yang terdapat dalam teori Takmilah bakal diaplikasikan dalam kajian ini bagi memantapkan lagi analisis kajian. Berdasarkan kajian, menunjukkan bahawa nilai-nilai Islam sememangnya terkandung dalam ceritacerita rakyat ini dan berpotensi sebagai medium pendidikan yang efektif kepada khalayak.
\end{abstract}

Kata kunci: Nilai Islam, cerita rakyat, masyarakat Melayu, Teori Takmilah, pendidikan

\section{REFLECTION ON ISLAMIC VALUES IN A COLLECTION OF 366 MALAYSIAN FOLKLORES: A TAKMILAH APPROACH}

\begin{abstract}
Folklore is no stranger among the ancient Malay community. Unfortunately, it is increasingly forgotten by today's generation. Folklore contains Islamic values that can be used as an example to the people. Creativity Malay folklore in the process not only to entertain, but also educate people to the values of Islam. This study is based on the cluster of previous studies that are found to still lack research, especially on aspects of Islamic values. This study seeks to open the eyes of society on Islamic values in folklore. The objective of this study is to identify and analyze the Islamic values found in the text of Collection of 366 Malaysian Folklores which is able to educate the community in a better direction. This study reviews some of the folk tales contained in the text of Collection of 366 Malaysian Folklores. Next, this study uses qualitative methods as a research method and Takmilah theory is used as a deductive study that will strengthen the analysis section. The three main principles found in Takmilah theory will be applied in this study to further strengthen the analysis of the study. Based on studies, it shows that Islamic values are indeed contained in these folklores and have the potential to be an effective educational medium for the audience.
\end{abstract}

Keywords: Islamic values, folklore, Malay community, Takmilah Theory, education 


\section{Pengenalan}

Cerita rakyat merupakan sastera milik masyarakat Melayu yang diperturunkan daripada satu generasi kepada satu generasi. Cerita rakyat berperanan sebagai panduan, mengandungi nilai dan pengajaran yang dihasilkan oleh masyarakat Melayu bersama nilai kreativiti yang dimiliki oleh mereka. Mohd Firdaus Che Yaacob (2018) menyatakan bahawa cerita rakyat merupakan suatu hasil pengucapan secara lisan yang disampaikan oleh nenek moyang pada zaman dahulu kala, bersifat mudah difahami, memiliki hiburan yang mencuit hati, kaya dengan nilainilai murni yang dapat dipelajari oleh segenap lapisan masyarakat setempat untuk membentuk moral dan tingkah laku positif.

Secara ringkasnya cerita rakyat merupakan sebahagian daripada kesusasteraan Melayu lama yang bersifat lisan (mulut ke mulut), diperturunkan daripada satu generasi ke satu generasi, memiliki nilai-nilai pengajaran yang boleh dipelajari oleh segenap lapisan masyarakat serta bukan bersifat hiburan semata-mata. Oleh itu, pengkajian bersifat akademik sewajarnya dijalankan untuk memastikan khazanah Melayu dapat didokumentasi dan dimartabatkan serta menjadi wadah keunggulan ilmu dalam kalangan masyarakat hari ini. Kajian ini dijalankan untuk meneliti kehebatan sesuatu penghasilan plot sesebuah cerita rakyat yang kaya dengan pengolahan nilai-nilai Islam sebagai medium penting ke arah pembentukan moral dan akhlak mulia kepada generasi akan datang.

\section{Sorotan Kajian Lepas}

Beberapa sorotan kajian lepas terhadap cerita rakyat telah dibuat. Antaranya ialah kajian oleh Mohd Fahmi Ismail, Salmah Jan Noor Muhammad dan Mohd Sharifudin (2015) yang bertajuk "Cerita Rakyat Melayu: Suatu Analisis Pancaran Jati Diri Masyarakat Melayu Sebagai Cerminan Kebudayaan Melayu”. Kajian ini memfokuskan kepada aspek kepentingan nilai jati diri orang Melayu melalui cerita rakyat khususnya dalam teks Himpunan 366 Cerita Rakyat di Malaysia yang diselenggarakan oleh
Aripin Said dan Othman Puteh pada tahun 2015. Teori Ekologi Budaya telah diguna pakai dalam kajian ini bertujuan untuk memantapkan analisis kajian dengan pengaplikasian teori. Seterusnya, beberapa nilai jati diri telah digariskan seperti hemah tinggi, keberanian, kasih sayang, kerajinan, kerjasama dan rasional. Kesimpulannya, pengkaji berjaya mengangkat nilai jati diri yang terkandung dalam cerita rakyat kepada masyarakat untuk dijadikan pedoman dan mencapai keunggulan yang jitu.

Seterusnya, kajian oleh Mohd Firdaus Che Yaacob dan Normaliza Abd Rahim (2016) yang bertajuk "Nilai Baik Hati Menerusi Cerita Rakyat Melayu Terhadap Masyarakat Melayu: Suatu Aplikasi Teori Pengkaedahan Melayu". Kajian ini menumpukan perhatian terhadap nilai baik hati yang terkandung dalam cerita rakyat Melayu. Objektif kajian ini ialah mengenal pasti dan menganalisis nilai baik hati menerusi cerita rakyat Melayu, khususnya kepada masyarakat Melayu. Kajian ini mengaplikasikan teori Pengkaedahan Melayu dalam proses menganalisis kajian dan seterusnya mendapat hasil kajian yang sangat mantap. Hasil daripada analisis kajian menunjukkan nilai baik hati menerusi sifat belas kasihan, pemurah dan bertimbang rasa yang terkandung dalam cerita rakyat dapat mendidik masyarakat supaya mengamalkan nilai baik hati dalam kehidupan. Sebagai rumusannya, cerita rakyat merupakan antara medium pendidikan yang penting dalam membina peradaban Melayu agar lebih bermoral dan mendidik hati dengan nilai-nilai murni. Oleh itu, nilai baik hati yang terkandung dalam cerita rakyat Melayu harus ditonjolkan kepada masyarakat terutamanya masyarakat Melayu itu sendiri.

Selain itu, kajian oleh Delas Sentano (2017) yang berjudul "Transcoding Intangible Heritage: The Folklores Stories of Malaysia" menyentuh tentang isu memelihara cerita rakyat di Malaysia melalui media audio visual. Pengkaji berpendapat bahawa cerita rakyat sebagai warisan tidak ketara ini harus dipelihara dan dikekalkan dengan pelbagai cara. Cerita rakyat di Malaysia menghadapi cabaran dalam 
era digital dan pengetahuan tradisional terhadap cerita rakyat semakin dilupakan. Sehubungan itu, pengkaji berasa bertanggungjawab untuk memelihara cerita rakyat di Malaysia melalui audio visual. Batasan kajian ini tertumpu kepada analisis terhadap cerita rakyat yang bertajuk Mah Meri dan Iban dan Pua Kumbu. Usaha murni ini seharusnya diteruskan juga oleh rakyat Malaysia supaya khazanah ini terus terpelihara.

Selanjutnya, dalam kajian yang dibuat Mohd Firdaus Che Yaacob (2018) yang bertajuk "NilaiNilai Murni dalam Naratif Lisan di Lembangan Sungai Pengkalan Datu, Kelantan: Satu Penelitian Pengkaedahan Melayu" menumpu kepada aspek nilai murni yang terkandung dalam naratif lisan cerita rakyat di lembangan Sungai Pengkalan Datu, Kelantan. Kajian ini memaparkan naratif lisan di Kelantan yang masih belum mendapat perhatian yang meluas dalam kalangan para pengkaji di negara ini. Rentetan itu, pengkaji telah menjalankan kajian ini dengan mengumpul seberapa banyak cerita rakyat daripada penduduk Lembangan Sungai Pengkalan Datu dan mengenal pasti nilai-nilai murni yang terkandung di dalamnya. Nilai-nilai murni tersebut dianalisis dengan menggunakan teori Pengkaedahan Melayu melalui pendekatan moral, dakwah dan kemasyarakatan. Hasil kajian mendapati bahawa cerita rakyat di Lembangan Sungai Datu memiliki nilai-nilai murni yang boleh dijadikan pedoman kepada masyarakat.

Kajian oleh Rosmani Omar, Md. Sidin Ahmad Ishak dan Siti Ezaleila Mustafa (2019) yang berjudul "Daripada Cetak Kepada Digital: Rekonstruksi Cerita Rakyat di Malaysia" turut disorot. Kajian ini membincangkan sejauh mana transformasi penyampaian cerita rakyat di Malaysia sesuai dengan perkembangan teknologi dan pengenalan Dasar Industri Kreatif Negara. Pengkaji telah mengenal pasti beberapa judul cerita rakyat yang telah diadaptasi kepada media digital dan format yang telah digunakan oleh para penerbit dalam proses pengadaptasian tersebut. Kajian ini telah menggunakan pendekatan rekonstruksi bagi memantapkan lagi analisis kajian. Dapatan kajian jelas menunjukkan bahawa, cerita rakyat di Malaysia masih belum berkembang selaras dengan perkembangan teknologi masa kini. Oleh itu, usaha yang lebih keras harus dilakukan bagi memelihara khazanah kebangsaan ini dan seterusnya memartabatkannya ke peringkat yang lebih tinggi.

Berdasarkan daripada sorotan kajian lepas, dapat dirumuskan bahawa kajian-kajian cerita rakyat lebih berfokus kepada nilai murni, nilai jati diri, nilai baik hati dan juga aspek pemeliharaan cerita rakyat. Tidak banyak kajian yang memfokuskan kepada aspek nilainilai Islam dalam cerita rakyat. Oleh itu, kajian terhadap aspek nilai-nilai Islam dalam cerita rakyat wajar dilakukan bagi membangunkan korpus pengkajian akademik mengenai cerita rakyat.

\section{Penyataan Masalah}

Pengkaji mendapati terdapat kelompongan dalam kajian melalui pengamatan terhadap sorotan kajian lepas. Terdapat sejumlah kajian yang telah diteliti oleh pengkaji iaitu Cerita Rakyat Melayu: Suatu Analisis Pancaran Jati Diri Masyarakat Melayu Sebagai Cerminan Kebudayaan Melayu oleh Mohd Fahmi Ismail, Salmah Jan Noor Muhammad dan Mohd Sharifudin (2015), Nilai Baik Hati Menerusi Cerita Rakyat Melayu Terhadap Masyarakat Melayu: Suatu Aplikasi Teori Pengkaedahan Melayu oleh Mohd Firdaus Che Yaacob dan Normaliza Abd Rahim (2016), Transcoding Intangible Heritage: The Folklores Stories of Malaysia oleh Delas Sentano (2017), NilaiNilai Murni dalam Naratif Lisan di Lembangan Sungai Pengkalan Datu, Kelantan: Satu Penelitian Pengkaedahan Melayu oleh Mohd Firdaus Che Yaacob (2018) dan Daripada Cetak Kepada Digital: Rekonstruksi Cerita Rakyat Di Malaysia oleh Rosmani Omar, Md Sidin Ahmad Ishak dan Siti Ezaleila Mustafa (2019).

Hasil daripada pengamatan terhadap kajian-kajian lepas, pengkaji mendapati bahawa kajian mengenai nilai-nilai Islam dalam cerita rakyat Malaysia masih belum diberi perhatian secara khusus oleh para pengkaji. Selain 
mengetengahkan nilai Islam dalam cerita rakyat, pengkaji juga bermatlamat untuk membuka mata masyarakat tentang kepentingan cerita rakyat yang layak dianggap sebagai khazanah yang tidak ternilai. Oleh hal yang demikian, kajian mengenai nilai-nilai Islam dalam cerita rakyat sangat wajar dilakukan bagi melunaskan permasalahan kajian ini. Kajian ini bakal merungkai dan memberi pencerahan mengenai nilai-nilai Islam khususnya melalui cerminan dan gambaran yang terkandung dalam teks Koleksi 366 Cerita Rakyat Malaysia.

Selain itu, kajian-kajian lepas jelas menunjukkan bahawa pengkajian terhadap cerita rakyat masih belum dilakukan secara meluas dan menyeluruh. Kajian boleh dilakukan melalui pelbagai perspektif, khususnya kajian nilai Islam yang dianalisis melalui perspektif atau daripada kaca mata Islam. Oleh itu, wujud rasa tanggungjawab dalam diri pengkaji untuk melakukan kajian terhadap cerita rakyat dengan melihat cerminan nilai Islam yang terkandung dalam cerita rakyat Malaysia dengan menggunakan pendekatan berteraskan Islam iaitu pendekatan Takmilah. Hasrat ini bukan sahaja bertujuan untuk mengisi kelompongan sorotan kajian lepas, malahan ingin merungkai dan membuka mata masyarakat tentang kepentingan menjaga khazanah cerita rakyat.

\section{Batasan Kajian}

Kajian yang dijalankan tertakluk kepada beberapa batasan iaitu fokus kajian hanya terhad kepada empat buah cerita rakyat yang dipilih dalam teks Koleksi 366 Cerita Rakyat Malaysia. Antara tajuk yang dipilih ialah Mengapa Pinggang Kerengga Ramping, Bawang Putih Bawang Merah, Kaca Bertukar Emas dan Raja Kuyuk. Teks Koleksi 366 Cerita Rakyat Malaysia ini mengandungi 366 buah cerita yang dikumpul dari setiap pelusuk negeri di Malaysia. Teks ini diterbitkan oleh Edukid Publication Sdn. Bhd. pada tahun 2017. Teks ini diselenggara oleh Zainariah Abdul Wahab, Nur Syafiqa Yusoff dan Fatimah Abdul Nasir.

Seterusnya, kajian ini menggunakan teori Takmilah melalui beberapa prinsip bagi memantapkan lagi analisis perbincangan. Prinsip Takmilah dibataskan kepada empat prinsip selaras dengan batasan terhadap tajuk cerita rakyat yang dipilih. Antara prinsip yang dipilih ialah khalayak dengan sastera, sastera dengan ilmu, khalayak bertujuan memupuk mereka ke arah insan Kamil (sempurna) dan keislaman yang bersifat Akmal (sempurna). Pemilihan teori Takmilah dalam kajian ini dilihat sangat bertepatan dengan objektif kajian iaitu cerminan nilai dalam cerita rakyat melalui teks Koleksi 366 Cerita Rakyat Malaysia. Hal ini kerana ia berhubung kait antara nilai Islam dalam cerita rakyat dengan masyarakat atau khalayak.

\section{Metodologi Kajian}

Kajian ini bersifat kualitatif iaitu kaedah kepustakaan dan analisis teks. Kepustakaan merujuk kepada kaedah yang digunakan oleh pengkaji atau penyelidik untuk mendapatkan data atau maklumat daripada bahan-bahan atau dokumen yang sedia ada. Pengkaji telah berkunjung ke beberapa buah perpustakaan dengan tujuan untuk mengumpul seberapa banyak bahan dan sumber rujukan tentang kajian cerita rakyat dan teori Takmilah. Antara perpustakaan yang dikunjungi termasuklah Perpustakaan Universiti Malaysia Kelantan, Perpustakaan Awam Kelantan (PPAK), dan Dewan Bahasa dan Pustaka Wilayah Timur (DBPWT).

Manakala teks pula merujuk kepada teks kajian iaitu Koleksi 366 Cerita Rakyat Malaysia. Empat buah cerita rakyat dipilih dalam koleksi ini, difikirkan sesuai kerana mengandungi nilainilai Islam.

Seterusnya, pengkaji turut membincangkan tentang teori Takmilah secara terperinci. Menurut Tirto Suwondo (2005), teori Takmilah berkait rapat dengan falsafah al-Quran dan prinsip-prinsip asas dalam Islam. Oleh itu, teori ini merupakan teori kesusasteraan Islam. Kesusasteraan bukan setakat kreativiti sematamata, malahan perlu melibatkan prinsip-prinsip Islam supaya timbul nilai-nilai Islam sekali gus memberi kesedaran kepada khalayak. Oleh itu, kesusasteraan Islam mestilah syumul 
dan bertunjangkan nilai-nilai Islam. Teori Takmilah diperkenalkan oleh Shafie Abu Bakar. Beliau merupakan seorang pensyarah di Jabatan Persuratan Melayu (JPM) Universiti Kebangsaan Malaysia. Teori ini dianggap satu-satunya teori sastera Islam di Malaysia yang memberi penekanan analisis dan kritikan bersandarkan secara langsung kepada konsep tauhid. Penciptaan teori ini telah memberi sumbangan yang amat besar dengan membuka jalan kepada para sarjana dan pengkritik untuk melakukan kajian, analisis, ulasan dan kritikan berasaskan prinsip-prinsip keislaman.

Teori Takmilah terhasil daripada pembentangan beberapa siri kertas kerja yang membincangkan teori dan konsep sastera Islam. Pada peringkat awal, satu kertas kerja telah dibentangkan oleh Shafie Abu Bakar berjudul Sastera Islam: Teori Pengindahan Dan Penyempurnaan Dalam Rangka Tauhid di Port Dickson pada 29-31 Oktober 1992 (Shafie Abu Bakar, 1997). Walau bagaimanapun, istilah Takmilah belum lagi muncul sebagaimana yang difahami hari ini. Perbincangan umum dalam kertas kerja itu, ternyata telah membuahkan idea kepada beliau untuk menggagaskan satu kerangka teori yang boleh digunakan sebagai landasan kritikan dan analisis terhadap karya sastera Islam. Terdapat tujuh prinsip dalam teori Takmilah iaitu prinsip ketuhanan yang bersifat Kamal, prinsip kerasulan sebagai insan Kamil, prinsip Islam yang bersifat Akmal, prinsip Ilmu dengan sastera yang bersifat Takamul, prinsip sastera yang berciri estetik dan bersifat Takmilah, prinsip pada pengkarya yang seharusnya mengistikmalkan diri dan prinsip khalayak bertujuan memupuk mereka ke arah insan Kamil.

\section{Prinsip Ketuhanan Bersifat Kamal}

Menurut Shafei Abu Bakar (1997), prinsip pertama dalam teori Takmilah ini menghuraikan hubungan dua sifat Allah SWT iaitu Kamal (sempurna) dan Jamal (keindahan). Kesempurnaan-Nya terpancar melalui makhluk ciptaan-Nya. Kedua-dua sifat ini mempunyai pertalian yang sangat erat dalam menghubungkan Allah SWT dengan manusia. Sehubungan itu, penelitian terhadap sifat Kamal dan Jamal ini dapat dilihat melalui kewujudan makhluk ciptaan-Nya, khususnya kejadian manusia yang merupakan sebaik-baik kejadian.

Dalam konteks sastera, manusia dan alam sering dijadikan fokus dalam menghasilkan sesuatu karya, sementara seni pula memfokuskan kepada keindahan. Perkaitan antara dua aspek tersebut menunjukkan kepentingan menerapkan unsur-unsur yang digariskan oleh Islam supaya mencapai kesempurnaan seperti yang digagaskan oleh teori Takmilah. Hal ini jelas menunjukkan bahawa dua sifat Allah SWT tersebut saling berkait dalam dunia sastera.

\section{Prinsip Rasul sebagai Insan Kamil}

Menurut Shafei Abu Bakar (1997), prinsip Takmilah yang kedua iaitu prinsip kerasulan sebagai insan Kamil mempunyai pertalian dengan Rasulullah SAW sebagai insan Kamil yang mempunyai pertalian dengan istilah "Kamal" bererti sifatAllah yang Maha Sempurna. Menurut Kamariah Kamaruddin (2016), sifat yang ada pada Rasulullah SAW sebagai insan Kamil (sempurna) ini membuktikan kewujudan manusia dengan sebaik-baik kejadian yang seterusnya dapat dijadikan qudwah hasanah (contoh tauladan) kepada manusia dalam merealisasikan kehidupan lebih baik.

\section{Prinsip Islam Bersifat Akmal}

Prinsip yang ketiga ialah prinsip Islam yang bersifat Akmal menjelaskan Islam merupakan satu-satunya agama yang diredai-Nya dan ia merupakan agama yang sempurna dari segenap aspek.

\section{Prinsip Hubungan Sastera dengan Ilmu}

Prinsip keempat melihat hubungan sastera dengan ilmu yang mempunyai pertalian dengan diri sendiri khususnya melalui akal dan hati. Hal ini menjelaskan bahawa ilmu yang dibawa dalam kandungan sastera seharusnya berhubung kait dengan diri sendiri supaya makna dan mesej yang ingin disampaikan tidak terpesong. 


\section{Prinsip Sastera Berciri Estetik}

Prinsip kelima pula melihat sastera yang berciri estetik ini dari dua aspek iaitu keindahan lahiriah dan keindahan maknawi. Kedua-dua aspek ini terjalin dengan indah dan berupaya berdiri sebagai sebuah karya sastera yang boleh memberi manfaat kepada khalayak.

\section{Prinsip Pengkarya Mengistikmalkan Diri}

Prinsip yang keenam ini pula bermaksud pengkarya itu sendiri perlu melengkapkan diri dengan ilmu-ilmu keislaman dan ilmu-ilmu yang berhubung dengan sastera iaitu seorang sasterawan muslim seharusnya tergolong dalam golongan yang alim dalam ilmu-ilmu Islam terutama ilmu yang ingin disampaikan kepada khalayak.

\section{Prinsip Hubungan Khalayak dengan Karya}

Prinsip yang ketujuh ialah hubungan antara khalayak dengan karya sememangnya tidak dapat dipisahkan. Oleh itu, sesebuah karya sastera Islam perlulah berunsurkan pendidikan, dakwah, menanam nilai-nilai tauhid, kekudusan, keagungan Tuhan, jihad, penentangan terhadap kebatilan dan sesuatu yang mengajak ke arah kebaikan.

\section{Justifikasi Pemilihan Teori Takmilah}

Pengkaji menggunakan teori Takmilah kerana bertepatan dengan aspek kajian, yakni nilainilai Islam yang terdapat dalam cerita rakyat. Tambahan lagi, dasar teori Takmilah merupakan ajaran Islam yang telah diwahyukan oleh Allah SWT. Selain itu, nilai-nilai Islam yang dikenal pasti akan dianalisis menggunakan prinsip Takmilah bagi memantapkan lagi huraian. Selanjutnya, nilai-nilai Islam dilihat sangat rapat dengan masyarakat Melayu dan bertepatan dengan prinsip Takmilah yang menggariskan jalinan antara karya sastera dengan khalayak. Oleh itu, pemilihan teori Takmilah sebagai deduktif adalah sangat tepat dalam kajian ini. Justeru, berdasarkan kepada paparan watakwatak yang terkandung dalam cerita rakyat
Melayu menggambarkan kisah-kisah orang Melayu pada suatu ketika dahulu yang akrab dengan amalan baik atau murni berlandaskan kepada ajaran Islam yang sebenar.

\section{Dapatan Kajian dan Perbincangan}

Pada bahagian ini, nilai-nilai Islam yang terkandung dalam cerita-cerita rakyat yang dipilih dianalisis. Antara nilai tersebut ialah taat, pemaaf, bersyukur dan percaya kepada Allah SWT. Sehubungan itu, pengkategorian cerita rakyat dapat dilihat pada rajah di bawah:

\begin{tabular}{ll}
\multicolumn{1}{c}{$\begin{array}{c}\text { Jenis-jenis Cerita } \\
\text { Rakyat }\end{array}$} & \multicolumn{1}{c}{ Tajuk Cerita Rakyat } \\
\hline Cerita Binatang & $\begin{array}{l}\text { Mengapa Pinggang } \\
\text { Kerengga Ramping }\end{array}$ \\
\hline Cerita Legenda & $\begin{array}{l}\text { Bawang Putih Bawang } \\
\text { Merah } \\
\text { Raja Kuyuk }\end{array}$ \\
\hline Cerita Mitos & Kaca Bertukar Emas \\
\hline
\end{tabular}

Rajah 1: Pengkategorian cerita rakyat

\section{Nilai Taat}

Kajian ini mengutarakan nilai yang dianjurkan oleh Islam dalam cerita rakyat Malaysia. Antara nilai Islam yang diketengahkan termasuklah nilai taat kepada pemimpin. Selaras dengan itu, beberapa cerita rakyat telah dipilih sebagai batasan dalam kajian ini.

Menurut Lukman Hakim (2012), nilai taat dalam kaca mata Islam merupakan sebuah nilai yang dititipkan oleh Allah SWT kepada para nabi untuk diajar dan disebarkan kepada umat manusia supaya sentiasa mentaati pemimpin. Selain itu, M. Alifuddin Ikhsan (2017), menegaskan bahawa nilai taat kepada pemimpin dalam Islam menjadi nilai yang luhur dalam sesebuah masyarakat. Oleh itu, nilai taat kepada pemimpin sememangnya terkandung dalam ajaran Islam yakni dari zaman para nabi sebagai panduan kepada manusia zaman kini untuk mengamalkan nilai taat kepada pemimpin.

Nilai Islam pertama iaitu taat kepada pemimpin telah digambarkan dalam cerita rakyat 
yang bertajuk Mengapa Pinggang Kerengga Ramping. Hal ini jelas tergambar dalam petikan 1 di bawah:

\section{Petikan 1}

"Raja Kerengga bertitah, "Beta mahu semua rakyat mengikat perut kuat-kuat. Jika perut diikat, kita akan rasa kurang lapar. Beta sudah mencubanya." Semua rakyat kerengga taat kepada perintah raja mereka. Mereka mengikat perut masingmasing. Mereka berasa gembira kerana cara itu berkesan. Apabila banjir surut, mereka pun dapat mencari makanan seperti biasa".

(Zainariah Abdul Wahab, Nur Syafiqa Yusoff \& Fatimah Abdul Nasir, 2017).

Berdasarkan petikan 1, sumber teks mengetengahkan nilai taat dalam konteks taat kepada pemimpin. Nilai tersebut digambarkan melalui kisah tempat tinggal kerengga yang dilanda banjir lalu mengakibatkan mereka tidak dapat mencari makanan. Pemimpin mereka yakni Raja Kerengga telah menitahkan rakyatnya supaya mengikat perut. Walaupun perbuatan mengikat perut itu sesuatu yang mungkin memberi kemudaratan kepada mereka, namun mereka tetap melakukannya kerana sifat taat terhadap raja mereka sangat kuat. Hal ini dikatakan demikian kerana, mereka meletakkan seluruh kepercayaan terhadap Raja Kerengga selaku pemimpin mereka untuk menyelesaikan masalah yang sedang melanda.

Menurut perspektif Islam, nilai Islam yakni nilai taat kepada pemimpin ini sememangnya dituntut supaya dapat melahirkan sebuah masyarakat yang taat dan tidak melanggar perintah pemimpin. Dari sudut sosiobudaya pula, masyarakat Melayu khususnya pada zaman tradisional amat menitikberatkan aspek taat kepada pemimpin atau raja kerana telah menjadi sebahagian daripada budaya yang diamalkan secara turun-temurun. Oleh itu, setiap muslim dituntut supaya bersabar dalam mentaati perintah pemimpin walaupun bertentangan dengan kehendak sendiri selagi ia mendorong ke arah kebaikan. Sehubungan itu,
Islam menyeru supaya taat kepada pemimpin kerana ia adalah tanda kehebatan seorang muslim dalam sesebuah kehidupan dan sifat taat juga menjadi penyebab turunnya bantuan Allah SWT. Justeru itu, hal ini jelas menunjukkan nilai Islam iaitu taat sememangnya terkandung dalam cerita rakyat Malaysia.

Pengaplikasian teori ini dapat dilihat melalui salah satu prinsip dalam teori Takmilah iaitu khalayak dengan sastera. Prinsip ini menegaskan tentang hubungan khalayak dengan karya sastera tidak dapat dipisahkan. Hal ini dikatakan demikian kerana karya memainkan peranan penting dalam mempengaruhi pemikiran khalayak ke arah isu tertentu yang ingin diketengahkan. Menurut Shafei Abu Bakar (1997), dalam konteks Islam, sesebuah karya haruslah menerapkan unsur pendidikan, dakwah, menanam nilai-nilai tauhid, kekudusan, keagungan Tuhan, penentangan terhadap kebatilan dan sesuatu yang mengajak ke arah kebaikan. Tujuan unsur-unsur ini diterapkan adalah untuk mengajak khalayak atau pembaca mendekatkan diri kepada ajaran Islam dan mengelakkan terpesongnya kepercayaan terhadap Allah. Oleh itu, nilai taat ini haruslah diterapkan dalam sesebuah karya supaya dapat menyemai nilai murni dalam jiwa masyarakat.

\section{Nilai Pemaaf}

Nilai pemaaf menurut Roudlotul Jannah (2015), merupakan salah satu nilai yang dituntut dalam Islam kerana tanpa adanya sifat pemaaf tidak mungkin terciptanya kerukunan dan kedamaian dalam hidup. Menurut Siti Chadijah pula (2018), Islam menuntut umat manusia mengamalkan nilai pemaaf terutama dalam hubungan kekeluargaan bagi membentuk sebuah keluarga yang Sakinah. Sebagai rumusannya, nilai pemaaf amat perlu untuk diamalkan kerana ia memberi kebaikan untuk semua pihak dalam menjalani kehidupan yang penuh dengan kepelbagaian yang membawa kepada perselisihan.

Seterusnya, nilai pemaaf jelas digambarkan dalam cerita rakyat yang bertajuk Bawang Putih Bawang Merah. Hal ini dapat dilihat dalam petikan 2 di bawah: 
Petikan 2

"Mak Kundur dan Bawang Merah menangis dan meminta ampun. Bawang Putih yang baik hati meminta putera itu mengampunkan mereka".

(Zainariah Abdul Wahab, Nur Syafiqa Yusoff \& Fatimah Abdul Nasir, 2017).

Petikan 2 menggambarkan sifat pemaaf ditonjolkan oleh watak Bawang Putih yang baik hati kerana memaafkan watak antagonis yakni Mak Kundur dan Bawang Merah. Cerita rakyat ini menonjolkan nilai pemaaf yang penting dalam konteks kekeluargaan kerana boleh menghindarkan daripada terputusnya hubungan akibat berlakunya perselisihan dalam hubungan kekeluargaan. Sebagai seorang muslim, nilai pemaaf harus disemai dalam diri sebagai menzahirkan keunggulan peribadi seorang muslim. Nilai yang dianjurkan oleh Islam ini merupakan sifat nabi Muhammad SAW. Selain itu, nilai pemaaf amat rapat dengan aspek sosiobudaya masyarakat Melayu kerana masyarakat Melayu sentiasa mementingkan nilai pemaaf terutama bagi mengelakkan perselisihan daripada ia berterusan. Cerita rakyat ini berjaya menggambarkan nilai pemaaf melalui watak Bawang Putih dan seharusnya diambil iktibar oleh masyarakat.

Hal ini bertepatan dengan salah satu prinsip Takmilah iaitu prinsip sastera dengan ilmu yang harus dijalin dengan rapi. Konsep Takmilah yang mempunyai pertalian antara ilmu dengan sastera ini melibatkan akal dan hati (Shafei Abu Bakar, 1997). Cerita rakyat sememangnya disampaikan oleh seseorang yang berilmu tinggi dan memiliki akal dan hati yang baik supaya mampu memberi ilmu kepada khalayak. Hal ini berdasarkan cerita Bawang Putih Bawang Merah yang sarat dengan nilai khususnya nilai Islam dan pengajaran yang boleh dijadikan ilmu yang berguna dalam menjalani kehidupan berkeluarga. Nilai pemaaf yang ditonjolkan oleh watak Bawang Putih sangat penting untuk disemai dalam setiap diri ahli keluarga untuk mengelakkan konflik kekeluargaan daripada berpanjangan. Oleh itu, tukang cerita atau penglipur lara haruslah melengkapkan diri dengan ilmu dan mempunyai akal dan hati yang murni supaya cerita rakyat yang disampaikan dapat memberi ilmu dan manfaat kepada khalayak.

\section{Nilai Bersyukur}

Menurut Hamka (1983) nilai bersyukur merujuk kepada menggunakan sesuatu yang telah diberikan Allah SWT sesuai dengan fungsinya masing-masing seperti yang telah ditentukan oleh Allah SWT. Selanjutnya, menurut Raudlotul Jannah (2018), nilai bersyukur adalah tidak mengeluh sekiranya tidak mendapat apa yang dihajati dan sentiasa menghargai apa yang telah diperoleh. Berdasarkan pendapat ini, dapat difahami bahawa nilai bersyukur amat dituntut dalam Islam supaya sentiasa mendapat reda daripada Allah SWT di atas segala yang telah diberi oleh-Nya.

Selain itu, cerminan nilai bersyukur dapat dilihat dalam cerita rakyat yang bertajuk Kaca Bertukar Emas. Nilai besyukur dalam cerita rakyat ini merangkumi tiga aspek itu sentiasa bersyukur, baik hati dan sentiasa berdoa. Hal ini dapat digambarkan dalam petikan 3 di bawah:

\section{Petikan 3}

"Apabila wanita tua itu membuka guni itu, alangkah terkejutnya dia apabila mendapati wang emas bertimbun-timbun di dalamnya. Wanita tua itu mengucapkan syukur. Orang kaya yang mengintai dari luar pondoknya sungguh terkejut".

(Zainariah Abdul Wahab, Nur Syafiqa Yusoff \& Fatimah Abdul Nasir, 2017).

Petikan 3 di atas jelas menggambarkan nilai bersyukur wanita tua itu kepada tuhan kerana memberi rezeki yang melimpah-ruah. Wanita tua itu merupakan seorang yang miskin dan kerjanya hanyalah menjual kayu api. Namun begitu, dia merupakan seorang yang selalu bersyukur dan tidak pernah mengeluh dengan rezeki yang diperolehinya. Berdasarkan kaca mata Islam, syukur merupakan perbuatan 
berterima kasih kepada Allah dan pengakuan yang tulus atas nikmat yang diberikan-Nya. Sehubungan itu, aspek sosiobudaya masyarakat Melayu juga mementingkan cara hidup yang sentiasa bersyukur dengan setiap rezeki yang diperoleh supaya dapat membentuk sebuah kehidupan yang tenang dan sentiasa merasa cukup. Dia juga mempunyai hati yang baik kerana sanggup melepaskan ikan haruan setelah berpendapat ikan juga mengalami kesusahan yang sama dihadapi olehnya. Hal ini dapat dilihat dalam petikan 4 di bawah:

\section{Petikan 4 \\ "Sewaktu ingin menangkap ikan-ikan itu, tiba-tiba wanita tua itu terfikir. "Ikan- ikan ini sengsara sama seperti aku. Tidak mengapalah, mungkin ada rezeki lain untukku”.}

(Zainariah Abdul Wahab, Nur Syafiqa Yusoff \& Fatimah Abdul Nasir, 2017).

Petikan 4 di atas jelas menunjukkan kemurnian hati wanita tua tersebut yang memikirkan nasib ikan haruan tersebut walaupun dirinya sendiri berasa lapar. Nilai sebegini amat dituntut dalam Islam kerana seorang muslim seharusnya memiliki hati yang penuh dengan kebaikan supaya lahir rasa belas ihsan terhadap sesama makhluk di atas muka bumi Allah SWT. Dalam konteks sosiobudaya masyarakat Melayu, nilai baik hati amat dititikberatkan dalam memupuk perasaan untuk menyumbangkan kebajikan kepada diri sendiri dan orang sekeliling secara tulus dan ikhlas. Antara nilai lain yang terkandung dalam cerita rakyat ini termasuklah nilai berdoa kepada Allah SWT agar dikurniakan rezeki yang mencukupi dalam kehidupan. Hal ini dapat dilihat dalam petikan 5 di bawah:

\section{Petikan 5}

"Rupa-rupanya ikan itu berdoa itu berdoa
agar Tuhan menurunkan hujan. Sebentar
cuma, hujan turun. Wanita tua itu pulang
ke pondoknya. Dia rasa bertenaga kembali.
Dia teringat akan ikan-ikan yang senasib
dengannya lantas menadah tangan memohon agar Tuhan mengurniakan rezeki. Dia berdoa dengan kuat selama tiga malam berturut-turut".

(Zainariah Abdul Wahab, Nur Syafiqa Yusoff \& Fatimah Abdul Nasir, 2017).

Petikan 5 di atas jelas menunjukkan bahawa wanita tua tersebut menunjukkan sifat bertaqwa kepada tuhan kerana menyerah sepenuhnya kepada tuhan dalam hal berkaitan dengan rezeki. Hal ini dikatakan demikian kerana, perbuatan berdoa selama tiga malam berturut-turut jelas menggambarkan sifat ketakwaan kepada tuhan. Islam sangat menuntut umatnya supaya bertakwa dengan cara berdoa kepada Allah SWT untuk meminta segala yang diinginkan. Seterusnya, dalam konteks sosiobudaya masyarakat Melayu, nilai bertakwa kepada Allah SWT sentiasa dipupuk kerana masyarakat Melayu lazimnya sememangnya dituntut untuk mengamalkan nilai bertakwa selaras dengan ajaran Islam. Oleh itu, cerita rakyat ini jelas mendidik masyarakat Melayu untuk sentiasa menanam nilai bertakwa kepada Allah SWT supaya hidup sentiasa diberkati oleh rahmat-Nya.

Berdasarkan teori Takmilah melalui prinsipnya yang melengkapi iaitu prinsip khalayak, prinsip ini ditemui melalui nilainilai bersyukur di atas supaya khalayak dapat menyerap nilai tersebut dan sekali gus dapat memupuk khalayak ke arah insan Kamil seperti yang dituntut. Didapati bahawa cerita ini mengajak masyarakat supaya sentiasa bersyukur dan merasa cukup dengan rezeki yang ditentukan oleh Allah SWT. Pendapat ini disokong oleh Kamariah Kamarudin (2016), iaitu karya sastera yang sempurna adalah karya yang dapat mengajak manusia agar sentiasa mendekatkan diri dengan agama agar tidak terpesong dalam mengharungi cabaran hidup yang penuh dugaan.

\section{Nilai Percaya kepada Allah SWT}

Menurut Imam al-Ghazali (1991), kepercayaan kepada tuhan adalah dengan melakukan ibadat yang disuruh oleh Allah SWT dan tentunya mempunyai sunnah-sunnah tertentu yang 
diamalkan oleh seseorang muslim. Kenyataan ini disokong oleh Kamariah Kamarudin (2011), bahawa kepercayaan kepada tuhan merupakan hubungan antara manusia dengan tuhan iaitu dengan meletakkan Allah SWT dalam hati. Oleh itu, nilai percaya kepada tuhan harus sentiasa ditanam dalam diri setiap muslim supaya kepercayaan dan ketaatan terhadap Allah sentiasa kukuh dan mantap.

Cerita rakyat yang seterusnya bertajuk Raja Kuyuk. Berdasarkan penelitian yang dilakukan, cerita rakyat ini mengandungi nilai Islam yang sangat ketara. Hal ini digambarkan dalam petikan 6 di bawah:

\section{Petikan 6}

"Raja Kuyuk berasa hairan lalu bertanya kepada raja Brunei Sultan Hasyim, "Maaf jika beta bertanya, apakah yang kamu semua lakukan?". Sultan Hasyim pun menjawab, "Kami semua mengerjakan sembahyang lima waktu. Kami menyembah Tuhan kami yang Maha Esa Allah SWT. Allah SWT yang menciptakan langit dan bumi, menciptakan segala makhluk di langit dan di bumi. Kami semua beragama Islam". Raja Kuyuk tertarik mendengar penjelasan Sultan Hasyim lalu menyatakan hasratnya untuk menganut agama Islam.

(Zainariah Abdul Wahab, Nur Syafiqa Yusoff \& Fatimah Abdul Nasir, 2017).

Berdasarkan petikan 6, jelas menunjukkan cerita ini menekan aspek agama sebagai tunjang utama dalam cerita Raja Kuyuk. Cerita rakyat ini berkisarkan Raja Kuyuk yang tertarik untuk menganut agama Islam selepas melihat perbuatan yang dilakukan oleh Sultan Hasyim yakni bersembahyang lima waktu ketika berada di negeri Raja Kuyuk iaitu Bukit Selingai. Rentetan itu, Sultan Hasyim sebagai watak yang berperanan sebagai pembuka minda dan pencetus kesedaran mengenai kehidupan beragama khususnya agama Islam terhadap Raja Kuyuk yang belum mengenali agama Islam. Dalam konteks sosiobudaya masyarakat Melayu, nilai percaya kepada Allah SWT diamalkan kerana lazimnya masyarakat Melayu beragama Islam dan nilai bertakwa ini telah menjadi budaya diamal selepas kedatangan lslam. Gambaran mengenai nilai percaya terhadap Islam dan Allah SWT sangat jelas disampaikan dalam cerita rakyat ini dan mengajak khalayak untuk lebih memahami agama Islam.

Pengaplikasian teori Takmilah melalui prinsip keislaman yang bersifat Akmal (sempurna) dapat dilihat dalam teks ini. Prinsip agama Islam yang bersifat dengan sifat syumul bermaksud Islam untuk seluruh umat manusia (Shafei Abu Bakar, 1997). Cerita Raja Kuyuk merupakan sebuah karya sastera rakyat yang berjaya mencerminkan nilai Islam dengan jelas. Sepertimana yang ditegaskan oleh Kamariah Kamaruddin (2016), sastera yang baik dan bermutu adalah dapat memupuk masyarakat ke arah kemurnian dan kesejahteraan.

\section{Kesimpulan}

Penelitian terhadap cerminan nilai-nilai Islam dalam buku Koleksi 366 Cerita Rakyat Malaysia mendapati cerita rakyat Melayu mengandungi pelbagai nilai Islam yang patut diambil dan diterapkan ke dalam masyarakat. Nilai-nilai Islam yang terkandung dalam cerita rakyat seharusnya dijadikan teladan kepada setiap lapisan masyarakat dan diwarisi kepada generasi akan datang. Melalui teori Takmilah menyerlahkan lagi nilai-nilai Islam yang terdapat dalam cerita rakyat yang dikaji. Penilaian terhadap prinsip Takmilah membuktikan wujudnya jalinan antara prinsip Takmilah dengan nilai-nilai Islam dalam cerita rakyat. Teori ini bukan hanya medium untuk menekankan aspek hubung kait antara karya sastera dengan nilai-nilai, tetapi memberi kesedaran kepada pengkarya dan khalayak mengenai kepentingan ajaran Islam terhadap institusi kemasyarakatan. Oleh itu, melalui kajian yang dijalankan dapat menjelaskan bahawa cerita rakyat sarat dengan nilai-nilai Islam yang boleh dijadikan ikutan dalam masyarakat supaya dapat melahirkan sebuah masyarakat yang diberkati dan diredai Allah SWT. 


\section{Penghargaan}

Dengan Nama Allah Yang Maha Pemurah dan Maha Penyayang segala puji dan syukur kepada Ilahi, Yang Maha Pengampun lagi Maha Mengasihani, selawat dan salam ke atas junjungan Rasul, Muhammad SAW.

Pertamanya, saya memanjatkan setinggitinggi kesyukuran ke hadrat Allah SWT kerana atas segala rahmat-Nya dan izin-Nya, artikel ini dapat dihasilkan. Saya ingin merakamkan jutaan terima kasih dan penghargaan kepada pensyarah saya, Dr. Mohd Firdaus Che Yaacob atas kerjasama, teguran dan nasihat yang ikhlas serta sokongan moral sepanjang saya menyelesaikan artikel ini. Saya juga ingin merakamkan rasa penghargaan buat Journal of Business and Social Development (JBSD) kerana memberi peluang dan kepercayaan untuk menerbitkan artikel ini. Semoga dengan kepercayaan ini akan memberi nilai tambah dalam dunia akademik agar terus maju jaya pada masa akan datang.

\section{Rujukan}

Abd. Rahim Abd. Rashid. (1993). Pendidikan nilai merentasi kurikulum KBSM. Kuala Lumpur: Penerbit Dewan Bahasa dan Pustaka.

Delas Santano. Transcoding Intangible Heritage: The Folklores Stories of Malaysia. (2017). Pacific Neighbprhood Consortium Annual Conference and Joint Meeting (PNC).

Tainan, Taiwan, 7-9 November.

Hamka. (1983). Tafsir al-Azhar Juz XIII. Jakarta: Pustaka Panjimas.

Hashim Musa. (2008). Hati budi Melayu: Pengukuhan menghadapi cabaran abad ke21. Selangor, Serdang: Penerbit Universiti Putra Malaysia.

Imam Ghazali. (1991). Akhlak seorang Muslim (Abu Laila \& Muhammad Tohir, Ed.). Kuala Lumpur: Victory Agency.

Jumali Selamat. (2001). Nilai-nilai dalam pantun Melayu. Tesis Ijazah Sarjana Muda. Fakulti Bahasa Moden dan Komunikasi, Universiti Putra Malaysia, Selangor.
Kamariah Kamaruddin, Tengku Intan Marlina Tengku Mohamad Ali \& Mawar Safei. (2016). Takmilah, semiotik \& intertekstualiti dalam karya Melayu. Kuala Lumpur: Visual Print Sdn. Bhd.

Kamus Dewan. (2016). Kuala Lumpur: Dewan Bahasa dan Pustaka.

Lukman Hakim. (2012). Internalisasi nilai-nilai agama Islam dalam pembentukan sikap dan perilaku siswa Sekolah Dasar Islam Terpadu Al-Muttaqin Kota Tasikmalaya. Jurnal Pendidikan Agama Islam-Ta'lim, 10(1), 67-77.

M. Alifudin Ikhsan. (2017). Nilai-nilai cinta tanah air dalam perspektif Al-Quran. Jurnal Ilmiah Pendidikan Pancasila dan Kewarganegaraan, 2(2), 108-114.

Mohd Fahmi Ismail, Salmah Jan Noor Muhammad \& Mohd Sharifudin. (2015). Cerita rakyat Melayu: Suatu analisis pancaran jati diri masyarakat Melayu sebagai cerminan kebudayaan Melayu. International Journal of Language Education and Applied Linguistics, 3, 91100.

Mohd Firdaus Che Yaacob \& Normaliza Abd Rahim. (2016). Nilai baik hati menerusi cerita rakyat Melayu terhadap masyarakat Melayu suatu aplikasi teori pengkaedahan Melayu. Journal of Business and Social Development, 4(2), 48-57.

Mohd Firdaus Che Yaacob. (2018). Nilai-nilai murni dalam naratif lisan di Lembangan Sungai Pengkalan Datu, Kelantan: Satu penelitian pengkaedahan Melayu. Tesis Ijazah Doktor Falsafah. Fakulti Teknologi Kreatif dan Warisan. Universiti Malaysia Kelantan.

Mohd Taib Osman. (1989). Malay folk beliefs: An intergration of disparate elements. Kuala Lumpur: Dewan Bahasa dan Pustaka.

Mohd Rosli Saludin. (2007). Nilai-nilai Islam dalam Teromba. Bukit Mertajam, Pulau Pinang: Penerbit Goal Intelligence Publication. 
Nirwana Sudirman \& Zulkifley Hamid. (2016). Pantun Melayu sebagai cerminan kebitaraan perenggu minda Melayu. Jurnal Melayu, $15(2), 146-159$.

Roudlotul Jannah. (2015). Pemikiran Hamka tentang nilai-nilai pendidikan budi pekerti.

Tesis Sarjana. Program Studi Pendidikan Agama Islan. Salatiga.

Rosmani Omar, Md Sidin Ahmad Ishak \& Siti Ezaleila Mustafa. (2019). Daripada cetak Kepada digital: Rekonstruksi cerita rakyat di Malaysia. Melayu: Jurnal Antarabangsa Dunia Melayu, 12(2), 291-319.
Shafei Abu Bakar. (1997). Estetika dan Takmilah dlm. Mana Sikana. Pembangunan Seni dan Sastera. Bangi: Jabatan Persuratan Melayu FSKK.

Siti Chadijah. (2018). Karakteristik keluarga Sakinah dalam Islam. Jurnal Rausyan Fikr, 14(1), 113-128.

Tirto Suwondo. (2005). Teori Takmilah: Cara baru pemahaman sastra. Balai Bahasa Jawa Tengah: Badan Pengembangan dan Pembinaan Bahasa.

Zainariah Abdul Wahab, Nur Syafiqa Yusoff \& Fatimah Abdul Nasir. (2017). Koleksi 366 cerita rakyat Malaysia. Kuala Lumpur: Edukid Publication Sdn. Bhd. 